Faculty, department, institute and corporate home pages can provide a useful way of obtaining background information on the people that should be included as professional 'centres of influence', a term used by Jensen. The centres of influence are the people who can tip the balance in the search for a position by making a recommendation, an introduction, suggesting a contact or alerting young scientists to the most appropriate time and place to publish their work.

Someone who is considering a career in industry, for instance, might do well to start with corporate Web sites (see Table 2). Eli Lilly's site, for example, includes information about the company's postdoctoral training programme. According to Joreg Pfeifer, Lilly's director of research personnel, the company plans almost to double its number of postdoctoral research positions (from 40 to 70) in the next year. The company will be hiring across-the-board in up to 12 disciplines. The appointments will be for one year, renewable for up to a maximum of three years. Jensen likens networking to "building a pyramid from the top down". The top stone in the pyramid is often the undergraduate or graduate adviser.

Scientific meetings remain the best arena for developing contacts. Preparation is the key to successful network development at meetings. Compiling a list of potential contacts beforehand, with background information about each, is recommended. At meetings, Agre stresses a low-key approach such as asking a potential contact for advice, an opinion, additional contacts in the field or simply using the opportunity to discuss a mutual area of research interest. A direct question about a possible job does not gen-

\section{TABLE 2 CORPORATE WEB SITES}

ALSAC-St Jude's Children's Research Hospital http://www.stjude.org

Bayer Corporation

http://www.bayer.com/english/0000home.htm

Biotechnology Industry Organization

http://www.bio.org

Bristol-Myers Squibb Company

http://www.bms.com

Ciba Pharmaceuticals

http://www.ciba.com

Eli Lilly and Company

http://www.lilly.com

Glaxo Wellcome Inc.

http://www.glaxowellcome.co.uk

Hoffmann-La Roche Inc.

http://www.roche.com

Johnson \& Johnson

http://www.jnj.com

Pharmaceutical Research \& Manufacturers

of America

http://www.phrma.org

Pharmacia and Upjohn Inc.

http://www.pharmacia.se

Procter and Gamble Health Care

http://www.pg.com

Sandoz Pharmaceuticals

http://www.sandoz.com/

Warner-Lambert Company

http://www.warner-lambert.com

erally meet with success; however, asking a well-connected person for advice about job hunting is both good and normal, he says. The best place to prepare for meetings with potential contacts, according to Agre, is the library. Begin by compiling a list of contacts and then learn more about them.

Jensen also advises that the best networking is rooted in the information-gath-

\title{
NIH lends a hand with loan repayment
}

Houston. For Claire Esposito, a critical-care fellow in the Clinical Center at the US National Institutes of Health (NIH), the agency's student loan repayment policy seemed too good to be true. As it turned out there was no catch. Esposito, now in her second year of a research fellowship and with student debts that would cause many to lose sleep at night, says participation in NIH's loan repayment program $(\mathrm{LRP})^{*}$ has "relieved a significant financial stress", the monkey on one's back that follows one through medical school, residency training and afterwards. Esposito says she wanted to "learn the business of research" but was originally reluctant to embark on a two-year fellowship because it would mean two more years of struggling to get by on a training salary. She admits that the LRP changed her outlook and she now intends to stay at NIH beyond her original two-year commitment.

So what level of student debt is commonplace? According to the Association of American Medical Colleges (AAMC), the average student debt on graduating from medical school, for example, is about $\$ 70,000$. But Marc S. Horowitz, director of NIH's Office of Loan Repayment, believes this figure is "deceptively low" because it fails to take into account the additional interest accrued on those student loans during residencies and internships. At NIH, "we see candidates with $\$ 120,000$ and $\$ 130,000$ in debts".

With debts like these it is not hard to see why so many individuals (particularly MDs) find they have to moonlight to make ends meet early on in their careers. Many take the path of least resistance and are lured into higher paying jobs in the private sector. A neurologist employed in a basic science laboratory at $\mathrm{NIH}$ can expect to earn between $\$ 45,000$ and $\$ 55,000$, says Eugene O. Major, chief of the laboratory of molecular medicine and neuroscience in the National Institute of Neurological Disorders and Stroke. On the outside, if they were fully board-certified, "their income would be doubled".

Faced with salaries out of step with the private sector but a need to intensify its

* For more information on NIH's LRPs, contact the Office of Loan Repayment, tel. 1-800-528-7689, fax 301-480-5481, e-mail: mh18k@nih.gov. (A list of state and other loan repayment initiatives can be obtained from AAMC, Washington, DC, tel. 202. 828-0681, fax 202-828-1125.) ering process. Unfortunately, scientists often rely solely their $\mathrm{CV}$, thinking their science will sell itself, he says. According to Jensen, only about $15-20$ per cent of all open positions are advertised. "When you limit your job search to 20 per cent of the market you place unnecessary constraints on the already short supply of potential opportunities."

Brendan Horton

research efforts in the AIDS/HIV area, NIH implemented its first LRP in 1989 in the hope that the programme would provide the incentive necessary to attract bright young researchers into its intramural AIDS research programme. So far, more than 90 researchers (primarily MD and PhDs) have benefited, with almost $\$ 5$ million repaid in student debts.

Robert Yarchoan, a section head and senior investigator at the National Cancer Institute, has shepherded at least four people through the AIDS LRP over the years (all of whom are still involved in some

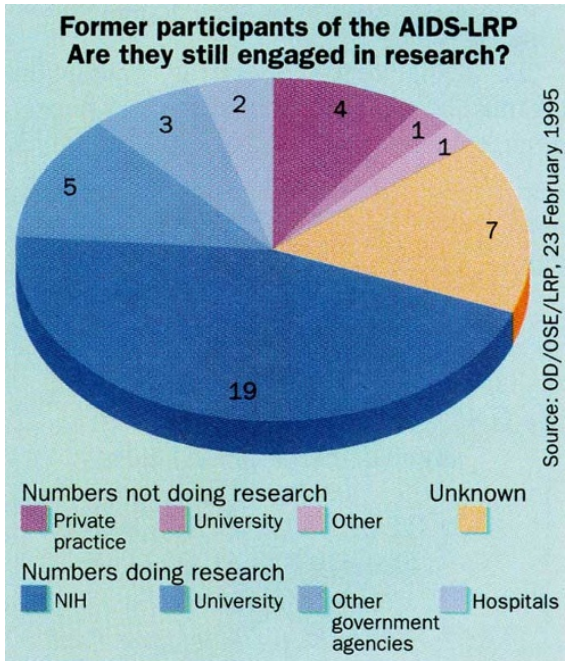

aspect of AIDS research, though not necessarily at $\mathrm{NIH}$ ). He says it is difficult to say with certainty that the programme has increased the cadre of investigators trained in AIDS research, although he suspects it has. Where he has found it particularly useful is in recruiting and retaining MDs, as it helps reduce their financial anxiety from large, outstanding medical school loans during the first couple of years of research, when many of them may otherwise get discouraged and go into private practice. Major's experience with the programme has been much the same. Having had three people participate in the LRP, and one about to apply, he believes it has enabled him to recruit good people to his laboratory and to keep people who are good for longer.

One measure of the success of the initiative is the extent to which it encourages people to stay in research - whether at NIH or elsewhere. A follow-up survey of 42 former AIDS research LRP beneficiaries (see pie 
chart) showed that of the 35 individuals who could be contacted, 29 are still in research, and of those, 25 are still involved in AIDSrelated research.

The loan repayment initiative was expanded in 1994 to include an LRP for clinical researchers from 'disadvantaged' backgrounds - a move made (in part) to help redress the balance between the number of basic and clinical researchers at NIH. Horowitz is keen to emphasize, however, that the programme is not solely targeting under-represented minorities: individuals from low-income families, as well as those with 'special' personal circumstances, are eligible for consideration. Twenty-two individuals have benefited so far.

Just because a position qualifies the holder for participation in an LRP does not mean the cheque is in the post. The awards are 'competitive', as are renewals, although about 70 per cent of those applying to the AIDS research LRP, and so far all of those applying to the clinical research programme, are successful, says Horowitz. In making its decision, the review committee pays close attention to the kind of supervision and training an individual will receive while at NIH.

To be eligible for consideration, individuals must be US citizens, nationals or permanent residents and must owe more than 20

\section{ADVERTISEMENT}

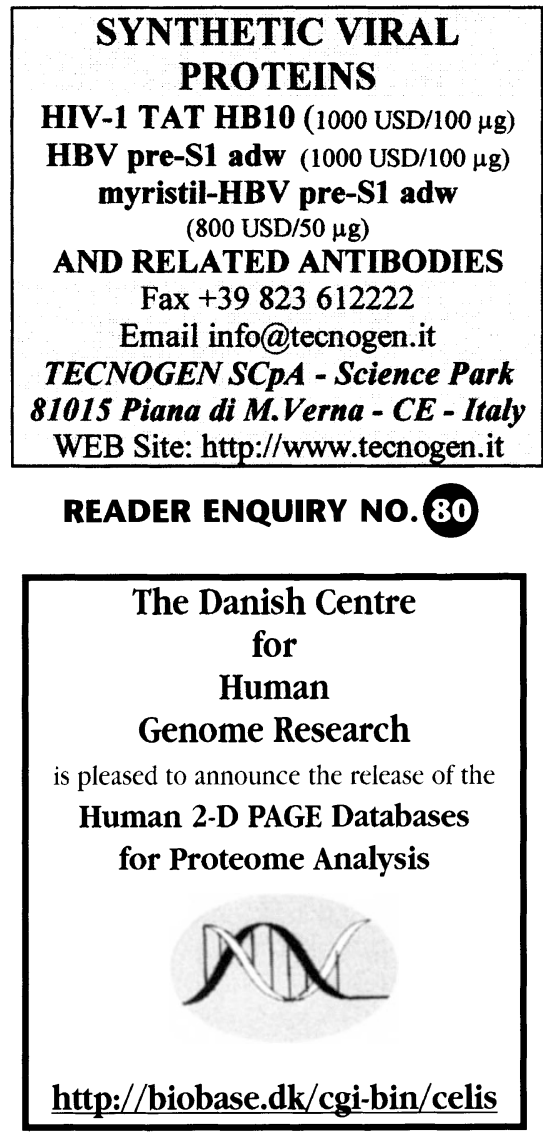

READER ENQUIRY NO.78

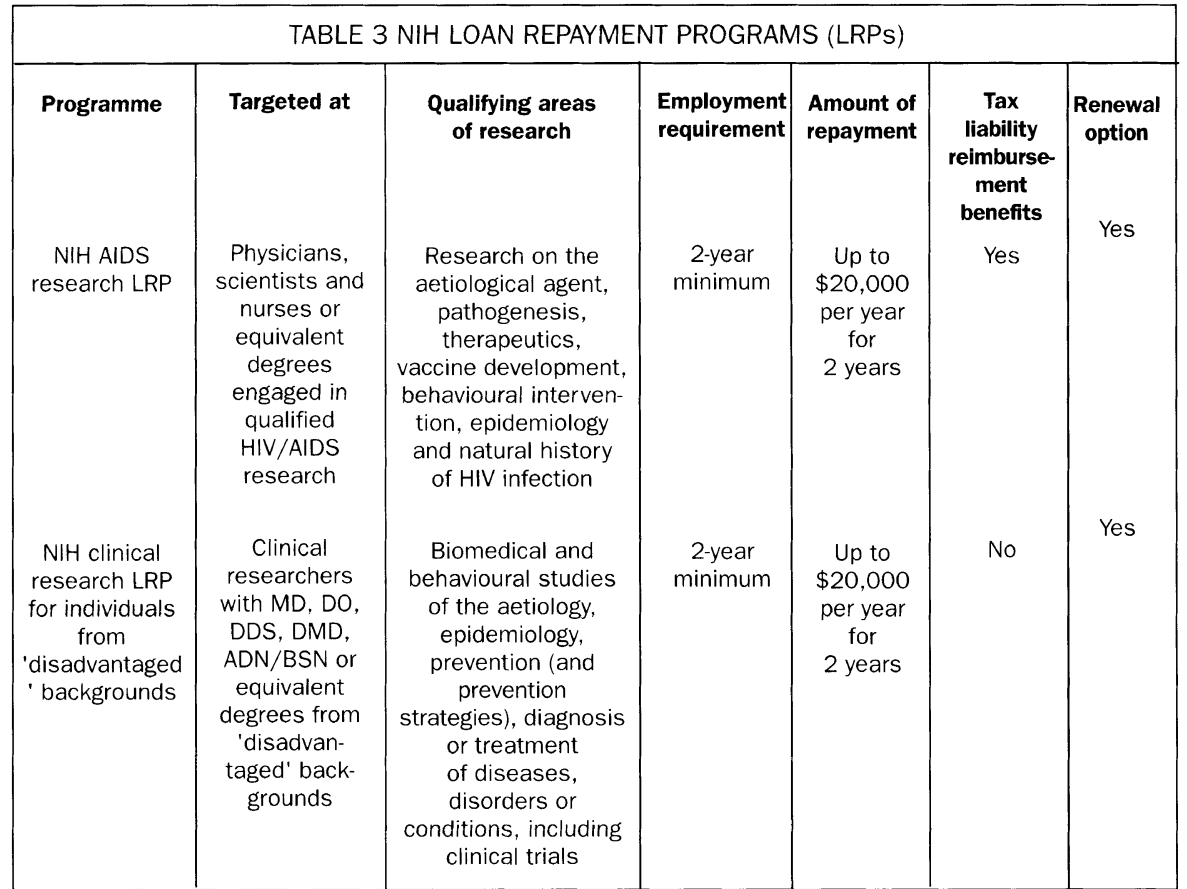

per cent of their annual NIH salary (see Table 3). Both programmes offer a maximum annual loan repayment of $\$ 20,000$, with the amount based in part on the proportion of an individual's qualifying debt relative to their NIH salary. In return, beneficiaries are required to commit themselves to at least a two-year stint at NIH. With the AIDS research LRP, NIH will also meet any increased tax liability that results, as payments made to a beneficiary are considered as 'income'. This is not currently offered with the clinical research LRP, although there is a move afoot to fix this inequity.

Whereas the existing programmes were implemented to respond to a specific identi-

fied need, Horowitz says that what NIH really needs now "is not a proliferation of disease-specific LRPs but a 'general' loan repayment authority" for tenure-track researchers, senior staff fellows and others who are not eligible for the existing programmes and who are prepared to spend at least three years at NIH. A general LRP was authorized by Congress in 1993, but a lack of available funds has so far prevented any progress on this front. If the appropriation is forthcoming for fiscal year 1997 (which begins on 1 October), and Horowitz is quietly optimistic, then NIH hopes to be able to fund between 15 and 20 individuals in the first year.

Diane Gershon

\section{$\mathrm{NIH}$ biomedical foundation finds its feet}

WORTH keeping an eye on in the coming months is the new National Foundation for Biomedical Research, now up and running having recently been incorporated in the State of Maryland as a tax-exempt (not-for-profit) foundation. The foundation hopes to raise money through donations from private citizens, corporations and philanthropic foundations to support special projects that fall within the mission of the National Institutes of Health (NIH) but which NIH is unable to fund adequately - or at all. Although the foundation was authorized by Congress in 1990 (and re-authorized in 1993) following a recommendation by the Institute of Medicine, Congress has yet to appropriate funds to cover its administrative costs.

It may be early days, but one of the areas where the foundation will probably focus its efforts and resources in the near term is in supporting research training, such as fellowships at the graduate and senior level - both at NIH and within the extramural community. Providing fund- ing for researchers to take sabbaticals in other laboratories, is another. The foundation also plans to support public education programmes, as well as to organize regional seminars and meetings that will bring primary health-care providers up to date with the latest research findings.

George J. Galasso, former associate director for extramural affairs at $\mathrm{NIH}$ and now the foundation's executive director, is busy putting flesh on the bones of the organization. Galasso, who retired from $\mathrm{NIH}$ last January after 28 years, says that although the foundation will seek input from $\mathrm{NIH}$, it will operate independently, under the guidance of a board of directors made up of prominent academics and corporate leaders. Nobel laureate Paul Berg, director of the Beckman Center at Stanford University School of Medicine, will serve as acting chairman until a permanent chairman is appointed. The nine-member board (there are two vacancies) will meet for the first time this month. 